\title{
DYSPHAGIA AFTER ANTIREFLUX FUNDOPLICATION: ENDOSCOPIC, RADIOLOGICAL AND MANOMETRIC EVALUATION
}

\author{
Disfagia após fundoplicatura anti-refluxo: avaliação endoscópica, radiológica e manométrica
}

Drausio Jeferson MORAIS, Luiz Roberto LOPES, Nelson Adami ANDREOLLO

From the Disciplina de Moléstias do Aparelho Digestivo e Gastrocentro, Departamento de Cirurgia, Faculdade de Ciências Médicas da Unicamp (Digestive Diseases and Surgical Unit and Gastrocenter Department of Surgery, School of Medical Sciences, State University of Campinas, Unicamp), Campinas, SP, Brazil.

HEADINGS - Dysphagia. Fundoplication. Videolaparoscopy. Manometry.

\section{Correspondence:}

Drausio J. Morais

E-mail: drausiomorais@yahoo.com.br

Financial source: none

Conflicts of interest: none

Received for publication: 09/06/2014

Accepted for publication: 21/08/2014

DESCRTORES - Disfagia. Fundoplicatura. Videolaparoscopia. Manometria.
ABSTRACT - Background: The transient dysphagia after fundoplication is common and most often disappears until six weeks postoperatively. Aim: Analyze a group of patients who presented late and persistent dysphagia postoperatively. Methods: Forty-one patients after Nissen fundoplication, 14 male and 27 female, mean age 48 year, were evaluated based on medical history, esophagogastroduodenoscopy, contrast radiographic examination and esophageal manometry. The results were compared with another 19 asymptomatic individuals. Results: Contrast radiographic examination of the esophagus revealed in six cases delayed emptying, characterizing that four patients had achalasia and two diffuse spasm of the esophagus. Esophageal manometry showed that maximal expiratory pressure of the lower sphincter ranged from 10 to $38 \mathrm{mmHg}$ and mean respiratory pressure from 14 to $47 \mathrm{mmHg}$, values similar to controls. Residual pressure ranged from 5 to $31 \mathrm{mmHg}$, and 17 patients had the same values as the control group. Conclusion: The residual pressure of the lower sphincter was higher and statistically significant in patients with dysphagia compared with those operated without dysphagia. Future studies individualizing and categorizing each motility disorder, employing other techniques of manometry, and the analysis of the residual pressure may contribute to understand of persistent dysphagia in the postoperative fundoplication.

RESUMO - Racional: A disfagia transitória após fundoplicatura é comum e na maioria das vezes desaparece até seis semanas após a operação. Objetivo: Analisar um grupo de pacientes que apresentaram disfagia tardia e persistente no pós-operatório. Métodos: Quarenta e um pacientes após fundoplicatura Nissen, 14 homens e 27 mulheres, com idade média de 48 anos, foram avaliados com base na história clínica, endoscopia digestiva alta, contraste exame radiográfico e manometria esofágica. Os resultados foram comparados com outros 19 indivíduos assintomáticos. Resultados: O exame radiográfico contrastado do esôfago revelou em seis casos atraso no esvaziamento, caracterizando que quatro tinham acalásia e dois espasmo difuso do esôfago. A manometria esofágica mostrou que a pressão expiratória máxima do esfíncter inferior variou de 10-38 mmHg e a pressão média respiratória $14-47 \mathrm{mmHg}$, valores semelhantes aos controles. A pressão residual variou de $5-31 \mathrm{mmHg}$, e 17 pacientes tinham os mesmos valores que o grupo controle. Conclusão: A pressão residual do esfíncter inferior foi maior e estatisticamente significativa em pacientes com disfagia comparados com aqueles operados sem. Estudos futuros individualizando e categorizando cada distúrbio de motilidade, empregando outras técnicas de manometria, e a análise da pressão residual podem contribuir para a compreensão da disfagia persistente no pós-operatório de fundoplicatura.

INTRODUCTION

T he gastroesophageal reflux disease (GERD) is considered the most common disease of the upper digestive tract in the western population. Surgery is its definitive treatment, since it restores the competence of the lower esophageal sphincter (LES) and cardia, by performing an anti-reflux valve (fundoplication), using the gastric fundus involving the abdominal esophagus 4 . The main effect of this procedure is a significant increase in pressure at the LES level associated with the reduction of transient relaxation of the sphincter ${ }^{21}$.

The functional alteration of LES is regarded as the most important etiological factor in the onset of $\mathrm{GERD}^{2}$. It must also be considered the motility disorders of the body of the esophagus, since approximately $75 \%$ of patients with symptoms of reflux disease that are not pronounced show changes. On the other hand, $50 \%$ of patients with pronounced symptoms have changes in esophageal motility. However, there is still controversy on this issue, whether the motility disorder is a cause or consequence of GERD. The normal function of the esophageal peristalsis is important in the prevention of peptic esophagitis, as it is the esophagus itself that removes the acid reflux, while saliva tends to neutralize it $\mathrm{it}^{9,12}$.

Videolaparoscopy surgical treatment is the most advance in the progress of surgery in recent years, allowing the complete reproduction of the method established in open surgery ${ }^{4,20}$. In the immediate postoperative, it is relatively common the development of transient dysphagia in some patients, which in most cases disappears up to six weeks postoperatively. However, a small number of them persist with postoperative dysphagia preventing them from eating normally and interfering with their daily habits ${ }^{10}$.

The aim of this study was to analyze a group of patients who presented late and 
persistent dysphagia postoperatively, after six months of fundoplication for GERD treatment.

\section{METHODS}

From June 1997 to December 2007, 41 patients who underwent fundoplication in community hospitals for GERD treatment, had severe dysphagia for at least six months and had great difficulty eating solid foods were referred and evaluated in the Unicamp University Hospital.

All cases presented symptoms of gastroesophageal reflux disease for long time. The indication for surgery was because of the constant dependence and the long treatment with proton pump blockers, and after stopping the medication the GERD symptoms would return. Patients included in the study presented hiatus hernia and esophagitis (degree A and B - Los Angeles classification) in esophagogastroduodenoscopy performed before surgery and also reported no dysphagia preoperatively and therefore did not undergo esophageal manometry previously.

The postoperatively evaluation included medical history and physical examination, performance of esophagogastroduodenoscopy, contrasted radiographic examination (barium swallow) of the esophagus, stomach and duodenum, and esophageal manometry. The serology for Chagas disease was negative in all cases.

Were 14 male and 27 female, aged 30-67 years and mean age of 48 years. The surgical technique used in all cases was laparoscopic Nissen fundoplication.

As a control group, there were another 19 asymptomatic individuals who had submitted to the same surgery and six months later presented no dysphagia. Similarly, indication for surgery was also due to hiatus hernia and same degrees of esophagitis, and the constant need of proton pump blockers to relieve their symptoms.

The esophagogastroduodenoscopy was performed by the same team of endoscopists, employing the Los Angeles classification.

The contrasted radiographic examination (barium swallow) was performed by an experienced radiologist analyzing the esophageal emptying time by fluoroscopy, swallowing a standardized solution of $250 \mathrm{ml}$ of barium contrast, diluted to $80 \%$. The esophageal emptying time was considered normal between five and seven seconds. When esophageal emptying time was recorded over seven seconds, was considered delayed emptying.

The esophageal manometry was performed after fasting for at least six hours, employing a catheter with eight side holes, with four radial holes being located at the same level and the other holes being located $5 \mathrm{~cm}$ from one another (Zynetics,Inc., Salt Lake City, UT, USA). The catheter was constantly perfused with water by a pneumo-hydraulic pump (Arndorfer Medical Specialties, Greendale, WI, USA) at a rate of $0.5 \mathrm{ml} / \mathrm{min}$. The catheter was passed through the nostril until reaching the stomach. The signals were captured for subsequent analysis in a digital computerized polygraph (Synectics Polygraph, Medtronic, Sweden).

The resting pressure of the LES was obtained by averaging the pressures obtained by the stationary pull-through technique, from one by one centimeter, from the gastric fundus. To analyze in detail the measurements of the LES, were included the maximal expiratory pressure, the mean respiratory pressure and the residual pressure. The maximal expiratory pressure is the LES pressure at the end-expiration, corresponding the point in the respiratory cycle where the diaphragmatic contribution to the observed pressure is at a minimum. The mean respiratory pressure is the LES in the midexpiration, corresponding the pressure component contributed by the diaphragm during respiration. And the residual pressure was definided as the difference between the lowest pressure measured during relaxation and the gastric baseline pressure and was evaluated after six swallows of $5 \mathrm{ml}$ water in the region of the LES, using the mean value obtained in the four radial channels located at the same level. The esophageal peristalsis was evaluated using five holes on side of the catheter, located at $5 \mathrm{~cm}$ distance from each other and positioned along the organ, being the first $3 \mathrm{~cm}$ above the proximal edge of the LES, after swallowing of $5 \mathrm{ml}$ water for 10 times at an interval of 30 seconds between swallows 22 .

Normal values were based on standardized population studies already published. The values of maximal expiratory pressure of the LES were obtained in the Brazilian study done by Lemme et al. ${ }^{15}$. The normal values for the mean respiratory pressure of the LES were proposed by Richter et al.22. Thus, the respective normal values considered were: maximal expiratory pressure $10-35 \mathrm{mmHg}$ and mean respiratory pressure $14-34 \mathrm{mmHg}$. And the values of the residual pressure found in control subjects were used for statistical comparisons. The criteria for the evaluation of the body of the esophagus were those defined by Richter et $\mathrm{al}^{22}$, being considered the esophageal motility disorders those proposed by Spechler \& Castell ${ }^{25}$, published recently seeking their standardization. By the other hand, the manometric findings for the characterization of ineffective esophageal motility were based on the criteria published by Leite et al. ${ }^{13}$.

The analysis of results was done by nonparametric MannWhitney test, comparing two independent groups, with a significance level of $5 \%{ }^{26}$

\section{RESULTS}

All patients reported clinical improvement of the symptoms of GERD with the completion of the fundoplication. However, after surgery, the patients developed symptoms of persistent dysphagia postoperatively with great difficulty eating solid foods.

\section{Upper gastrointestinal endoscopy}

The endoscopic examination carried out six months after surgery in patients with dysphagia revealed absence of esophagitis in all patients. The passage of the endoscope into the stomach was easy and there was no obstacle. The analysis of the gastric fundus revelead that the fundoplication was adjusted to the endoscope. Moreover, was verified the presence of fundoplication with total involvement of the endoscope and circular folds, and was concluded that none were above the diaphragm ring.

The endoscopy of control subjects who had no dysphagia, also performed six months after surgery, showed the absence of esophagitis, with easy passage of the device into the stomach. The analysis of fundoplication showed that it completely surrounded the endoscope with intraabdominal circular folds.

\section{Radiological examination}

Among patients with persistent dysphagia, six had delayed emptying of contrast and slight narrowing of the distal esophagus, without dilated organ in any of them. The remaining patients had normal radiological examination.

\section{Esophageal manometry}

Lower esophageal sphincter pressures

In the control group, maximal expiratory pressure ranged from $10-26 \mathrm{mmHg}$, mean respiratory pressure from 14-34 $\mathrm{mmHg}$, and residual pressure from $4-9 \mathrm{mmHg}$. The length of the LES was 3.5 to $5 \mathrm{~cm}$.

The maximal expiratory pressure had its minimum value recorded at $10 \mathrm{mmHg}$ and the maximum value at $38 \mathrm{mmHg}$ in patients with dysphagia. The mean respiratory pressure ranged from $14-37 \mathrm{mmHg}$.

Residual pressure in the group with dysphagia ranged from $5-31 \mathrm{mmHg}$, and from $4-9 \mathrm{mmHg}$ in patients without dysphagia (Table 1 and 2). 
TABLE 1 - Analysis of the LES in patients operated with dysphagia and in controls

\begin{tabular}{|c|c|c|c|c|}
\hline Groups & Lenght(cm) & $\mathrm{MEP}(\mathrm{mmHg})$ & $\mathrm{RP}(\mathrm{mmHg})$ & $\mathrm{MRP}(\mathrm{mmHg})$ \\
\hline Control (19) & 3.5 to 5 & 10 to 26 & 4 to 9 & 14 to 34 \\
\hline $\begin{array}{c}\text { Patients with } \\
\text { dysphagia (41) }\end{array}$ & 3.5 to 6.5 & 10 to 38 & 5 to 31 & 14 \\
\hline
\end{tabular}

TABLE 2 - Variations of the values of residual pressure in patients with dysphagia

\begin{tabular}{c|c|c|c|c|c|} 
Variation of RP (mmhg) & 5 to 9 & 10 to 12 & 13 to 15 & 16 to 18 & $>18$ \\
$\mathrm{~N}^{\circ}$. of patients & 17 & 8 & 12 & 2 & $2^{*}$
\end{tabular}

$\mathrm{RP}=$ residual pressure; $\left(^{*}\right)$ values three times higher compared to the control group

Statistical analysis comparing the values of the variable maximal expiratory pressure between the groups with and without dysphagia, showed no significant differences $(p=0.8701, p>0.050$. Similarly, when the values obtained from the variable mean respiratory pressure were compared between the two groups, there was no statistical significant difference $(p=0.8274, p>0,05$. The length of the LES ranged from $3.5 \mathrm{~cm}$ to $6.5 \mathrm{~cm}$ in these groups.

However, when were analyzed separately the residual pressure in patients with dysphagia, only 17 patients had values resembling the ones in the control group. Respectively, 12 patients had values $50 \%$ higher than controls, two had values twice as high and two other had values three times greater. The others had values around $30 \%$ higher than the control group.

The statistical analysis of the values obtained from the variable residual pressure showed significant difference $(p=0.0007, p<0.05)$. The Figure 1 shows these different pressures.

\section{Length of the lower esophageal sphincter}

Finally, comparing the changes of length of the LES obtained between the two groups, was found no significant difference to the statistical analysis $(p=0.6237, p>0.05$ (Figure 2$)$.

\section{Body of the esophagus}

The Table 3 below summarizes the changes in esophageal peristalsis recorded in control patients and patients with dysphagia. In the control patients, peristalsis was considered normal in all; however, among the 41 patients with dysphagia, peristalsis was normal in 20 and the others had changes that were characterized as total aperistalsis (achalasia), diffuse esophageal spasm, ineffective esophageal motility and nutcracker esophagus. In the latter patients, was recorded average values of the amplitudes of waves of $206 \mathrm{mmHg}, 208 \mathrm{mmHg}$ and $220 \mathrm{mmHg}$, respectively.

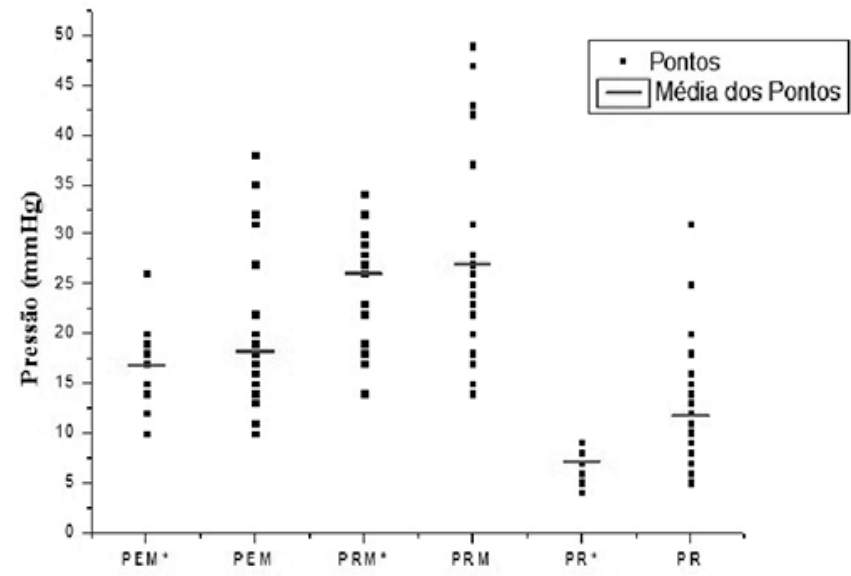

$\mathrm{MEP}^{*}=$ control; $\mathrm{MRP}^{*}=$ control; $\mathrm{RP}^{*}=$ control; $\mathrm{MEP}=$ maximal expiratory pressure $\mathrm{MRP}=$ mean respiratory pressure; $\mathrm{RP}=$ residual pressure; $\mathrm{RP}$ versus $\mathrm{RP}{ }^{*}$ $p=0.0007, p<0.05$

FIGURE 1 - Pressure variation of the LES for control group and the patients with dysphagia

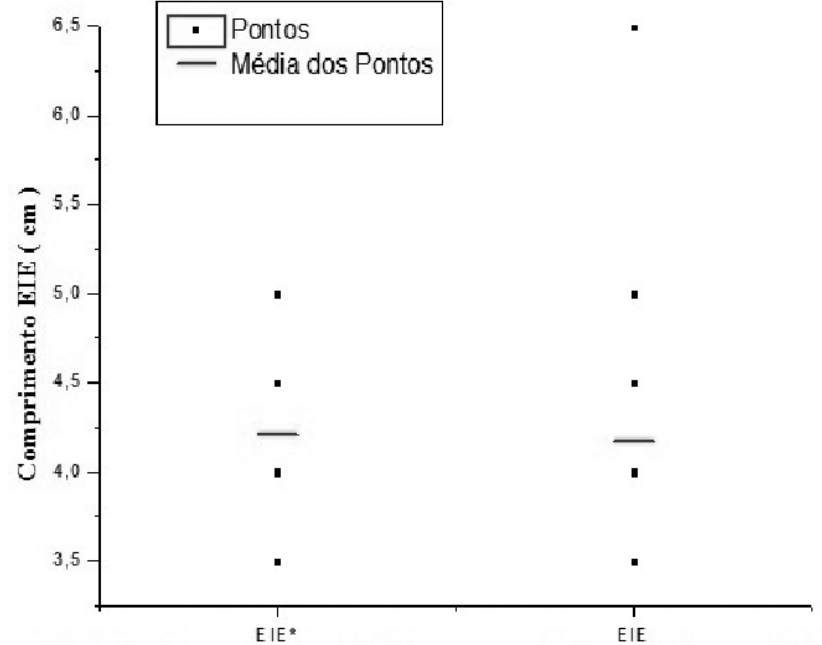

LES $^{*}=$ control - lower esophageal sphincter; LES versus LES* $p=0.6237, p>0.05$ )

FIGURE 2 - Changes of the length of the LES for control group and the patients with dysphagia

The analysis the manometry study of the body of the esophagus comparing the asymptomatic control group and the patients with dysphagia showed statistical significances $(p<0.0001, p<0.05)$. Moreover, by analyzing the changes in motility of the body of the esophagus recorded only in patients with dysphagia, no statistical differences were found $(p=0.0879, p>0.05)$ (Table 3).

TABLE 3 - Esophageal peristalsis of controls and patients with dysphagia

\begin{tabular}{|c|c|c|c|c|c|}
\hline Esophageal motility & Normal & Aperistalsis & NCE & DES & IEM \\
\hline $\begin{array}{c}\text { Controls (19) } \\
\text { Patients with }\end{array}$ & 19 & - & - & - & - \\
\hline dysphagia (41) & 20 & 4 & 3 & 4 & 10 \\
\hline
\end{tabular}

DES = diffuse esophageal spasm; IEM=ineffective esophageal motility $\mathrm{NCE}=$ nutcracker esophagus

On the other hand, analyzing separately the residual pressure of the 20 patients with dysphagia and normal peristalsis, were found that 12 patients presented higher residual pressure of the LES, ranging from $13-25 \mathrm{mmHg}$, and the respective values are shown in Table 4.

TABLE 4 - Patients with dysphagia and normal peristalsis, but with higher residual pressure

\begin{tabular}{|c|c|c|c|c|c|}
\hline Values of RP $(\mathrm{mmHg})$ & 13 & 15 & 20 & 25 & $>25$ \\
\hline $\mathrm{N}^{\circ}$. of patients & 6 & 3 & 2 & 1 & - \\
\hline
\end{tabular}

$\mathrm{RP}=$ residual pressure

\section{DISCUSSION}

Currently, GERD is among the most studied digestive diseases, affecting a significant population of subjects with daily symptoms, requiring prolonged treatment at high cost, and it may lead to serious complications, being evident its importance in society ${ }^{16}$. The surgical treatment using fundoplication is effective and has good long-term results ${ }^{19}$. Fundoplication performed by laparoscopy, since the first description in $1991^{4}$ gained popularity, thus becoming the first option as treatment, since the results obtained were similar to those achieved by conventional surgery, in terms of short-term and long-term success ${ }^{1,3,54,19,20}$. In a recent study of evidence-based medicine, Catarci et al. ${ }^{3}$ concluded that videolaparoscopic surgery is as safe and effective as open surgery, with the advantage of having less morbidity and shorter hospital stay ${ }^{3}$. 
Historically, the manometric studies were initiated in 1956; the record of the LES pressure has been the most used method to evaluate its competence ${ }^{14}$. Some authors, studying subjects with GERD, have found lower LES pressure values than that of the normal population ${ }^{14}$. Other authors have demonstrated that the pressure is not, alone, a good parameter to separate the population with physiological reflux from those with pathological reflux ${ }^{7,27}$. Clinical and experimental studies have shown that the length of the LES exposed to the pressure of the abdominal cavity, as a valve mechanism, plays an important role in preventing reflux ${ }^{17,27}$. It was also demonstrated that the competence of the cardia in preventing reflux depends not only on the pressure of the LES and its abdominal length, but also of its total length ${ }^{35}$. There is also to be considered the effect of the acute esophagogastric angle, the mucosal rosette and the effect of diaphragmatic crura. Recent studies show that the transient relaxation of the LES and the delayed gastric emptying are important factors in the pathophysiology of GERD ${ }^{11,14}$.

In the past, several studies have demonstrated that fundoplication performed by laparotomy determined a significant increase in the basal pressure of the LES 7 . Ireland et al. ${ }^{7}$, studying 18 patients undergoing open Nissen fundoplication, concluded that the residual pressure of the LES was the primary anti-reflux mechanism after this surgery. Kiroff et al. ${ }^{11}$ analyzing 41 patients demonstrated a significant increase in the residual pressure of the LES with swallowing of water after open surgery. Johnsson et al. ${ }^{8}$ found that fundoplication reduces the occurrence of transient relaxation of the LES induced by gastric dilatation ${ }^{24}$. These same results were also obtained after Nissen fundoplication performed by videolaparoscopy ${ }^{18,23}$.

This study included a group of patients with persistent dysphagia, who had difficulty eating solid foods even after six months or more after undergoing Nissen fundoplication for GERD treatment. The limitation of this study was that the patients enrolled had not performed the esophageal manometry preoperatively. However, they were operated in community hospitals where this diagnostic method is not always available. And subsequently were referred to the university hospital for evaluation and treatment of late and persistent dysphagia.

It is important to emphasize that dysphagia is a relatively common symptom until the $6^{\text {th }}$ week postoperatively, but its long-term persistence brings great discomfort as it prevents the patient to eat normally. Also its treatment depends on a careful and detailed evaluation and a good sense from the surgeon faced with this problem $3,7,8,10,18,20$.

The upper digestive endoscopy performed in all patients with dysphagia showed the absence of esophagitis. And the radiological examination showed that six cases presented delayed emptying of contrast and slight narrowing of the distal esophagus, but with normal esophageal diameter. The barium esophagogram in GERD provides good morphological evaluation of the body (shape and characteristics of esophageal transit of contrast material), helps to accurately acess esophageal emptying, the presence of hiatal hernia, stenosis, the motility, and identify the presence of reflux. After surgery, the esophagogram helps access esophageal emptying in cases with dysphagia, the location, integrity and length of the fundoplication, the presence of a recurrent hernia, and motility. Also helps the evaluation of gastric motility and emptying. Therefore it is important in patients with GERD ${ }^{17,20,24}$.

The motility changes of the body of the esophagus are often associated with GERD. Approximately $25 \%$ of patients with mild symptoms of reflux disease have motility changes, while $50 \%$ of patients with severe symptoms have changes in esophageal motility ${ }^{9}$. However, there are much controversies on this subject, with no consensus if the change of esophageal motility is a cause or consequence of GERD, and, besides, these patients have a higher prevalence and severity of dysphagia, respiratory symptoms, and chest pain, compared with those with normal esophageal motor function ${ }^{18,21}$.

These results demonstrated that 10 patients already suffered preoperatively from ineffective esophageal motility, were asymptomatics and developed persistent dysphagia after Nissen fundoplication. It is important to emphasize that these patients, like many others with GERD, presented no dysphagia before surgery. The changes regarding ineffective esophageal motility were evident and very significant, and only two patients had $100 \%$ peristaltic waves, but had marked hypocontractility of the body of the esophagus, respectively, one with all the waves with amplitudes below $30 \mathrm{mmHg}$ and other with $80 \%$ of waves with amplitude below 30 $\mathrm{mmHg}$. The remaining ones, besides showing dyskinesia, had "aperistaltic" or not propagated waves, ranging from 30-50\% of the swallows studied. Therefore, within the diagnostic criteria of the ineffective esophageal motility, there can be patients with changes within the threshold for their inclusion and others with marked changes. Thus, in this condition there is an important variation of manometric changes, some of which are pronounced and consequently will refer more obvious symptoms. The manometric changes of ineffective esophageal motility were described by Kahrilas et al. ${ }^{9}$ on a study of the effects of changes in peristalsis on the esophageal clearance volume and included in the abnormal functions of the incomplete transport of the bolus by the organ. However, more studies are needed aiming to make a division between the manometric changes found in ineffective esophageal motility and its possible repercussions on each patient.

The three patients who were diagnosed with nutcracker esophagus had average amplitude above $200 \mathrm{mmHg}$, two had residual pressure at the same levels of the control group and one had residual pressure of $15 \mathrm{mmHg}$. It is likely that the hypercontractility recorded in the body of the esophagus in the two patients with residual pressure equal to the control group already existed before the surgery. However, regarding the latter, it is difficult to say whether it is a result of the Nissen fundoplication or not. With the exception of this patient, all others who had high residual pressure did not have high amplitude esophageal waves. And about to the four cases of diffuse esophageal spasm, is believed that, as in the case of those suffering from achalasia, the presumable low LES may have contributed to the absence of dysphagia before surgery.

Among the group of 41 patients, nine had normal peristalsis, normal maximal expiratory pressure and median respiratory pressure, and residual pressure at the same levels as the control group. Thus, it was considered as manometric study within the normal range when it was not recorded manometric change justifying dysphagia. Wilshire et al. ${ }^{27}$ discuss the etiology of the postoperative dysphagia after Nissen fundoplication and the role of the esophageal motility disorders, the incomplete relaxation of the LES (high residual pressure), a constriction or a combination of these factors, concluding that impaired relaxation of the neo-high pressure zone, best discriminates those with dysphagia from asymptomatic patients. Myers et al. ${ }^{18}$ performed conventional manometry in patients with and without dysphagia, about five months after partial and total fundoplication. They found that patients with dysphagia who underwent fundoplication had high residual pressure relaxation of the lower esophageal sphincter. And Granderath et al. ${ }^{6}$, analysing a group of 50 patients with persistent or recurrent dysphagia after fundoplication, concluded in their study that the etiology in most of them was related to the closure of the diaphragmatic hiatus.

The residual pressure studied was higher in patients with dysphagia compared to those submitted to the same type of surgery and who presented no dysphagia, with statistical significance $(p<0.05)$. Among the patients with dysphagia, 
eight cases showed values increased of approximately $30 \%$ to the maximum value found in the control group, 12 had values of $50 \%$, two had twice the maximum value from this group, and two other had values three times greater than the maximum value of the control group. Mathew et al. ${ }^{7}$, in their studies showed a significant correlation between the high values of residual pressure with dysphagia for liquids in postoperative fundoplication.

Regarding the LES resting pressure in this study, there was no statistically significant difference between the groups with and without dysphagia. Slim et al. ${ }^{24}$ compared asymptomatic patients in postoperative fundoplication with those who had moderate or severe dysphagia, concluding that the LES pressure was significantly higher in the latter group.

The hypothesis is that patients with GERD included in the study reported no dysphagia preoperatively probably due presenting low LES pressure and therefore lacked an effective antireflux barrier at the level of the LES ${ }^{16}$. After fundoplication, they started to have an effective barrier, but esophageal peristalsis was abnormal. Thus, the equilibrium that existed for the progression of the bolus was disrupted with the creation of the effective barrier to prevent gastroesophageal reflux by Nissen fundoplication. Some cases had early-stage achalasia, without esophageal dilation in barium swallow examination of the esophagus.

Finally, this study shows that the dysphagia that could be present in motility disorders in patients with an effective barrier for gastroesophageal reflux may not revel itself when there is the presence of hiatal hernia and incompetence of the LES. It was demonstrated that high residual pressure was higher and statistically significant in patients with dysphagia, compared with those operated without dysphagia and, moreover, that changes in motility were more numerous in those who had dysphagia.

Future studies individualizing and, possibly, categorizing each change of esophageal motility and the LES pressure may contribute to the prevention of persistent dysphagia in the postoperative fundoplication.

\section{CONCLUSION}

The indication of preoperative esophageal manometry shows a more detailed analysis of the esophagus and LES, contributing to the best approach to be performed in patients with GERD and hiatal hernia. Changes of esophageal motility must be individualized and well researched before surgery, and it is certainly essential in patients with GERD associated with dysphagia. And, undoubtedly, it is also an important method in the evaluation of patients with postoperative dysphagia, which can greatly contribute, after careful consideration, to the proper conduct to be adopted in the treatment of these cases. Consequently, it is important to analyze the residual pressure of the LES, because may contribute to elucidate the etiology of dysphagia after fundoplication.

\section{REFERENCES}

1. Ackroyd R, Watson DI, Majeed AW, Troy G, Treacy PJ, Stoddard CJ. Randomized clinical trial of laparoscopic versus open fundoplication for gastro-oesophgeal reflux disease. Br J Surg. 2004;91:975-982.

2. Anderson K. Gastroesophageal reflux disease. Radiol Technol. 2010;81(3):251-68

3. Catarci M, Gentileschi P, Papi C, Carrara A, Marrese R, Gaspari A.L Grassi G.B. Evidence-Based Appraisal of Antireflux Fundoplication Ann Surg. 2004; 239(3): 325-37.

4. Dallemagne B, Weerts JM, Jehaes C. Laparoscopic Nissen fundoplication. A preliminary report. Surg Lapar Endosc. 1991;1:138
5. Felix, W.N.; Cecconello, I.; Zilberstein, B.; Pinotti, H.W. Manometry of the lower esophageal sphincter (evaluation of the present status). ABCD Arq Bras Cir Dig. 1987;2: 121-25, 1987.

6. Granderath FA, Schweiger UM, Kamolz T, Pointner R. Dysphagia after laparoscopic antireflux surgery: a problem of hiatal closure more than a problem of the wrap. Surg Endosc. 2005; 19(11):1439-46.

7. Ireland AC, Holloway RH, Toouli J, Dent J. Mechanisms underlying the antireflux action of fundoplication in the treatment of gastroesophageal reflux. Gut. 1993;34(3):303-8

8. Johnsson F, Holloway RH, Ireland AC, Jamieson GG, Dent J. Effect of fundoplication on transient lower esophageal sphincter relaxation and gas reflux. Br J Surg. 1977; 84:686-9.

9. Kahrilas PJ, Dodds WJ, Hogan WJ. Effect of peristaltic dysfunction on esophageal volume clearance. Gastroenterology 1988;94:73-80.

10. Kamolz T, Bammer T, Pointner R. Predictability of dysphagia after laparoscopic Nissen fundoplication. Am J Gastroenterol. 2000; 95 : 408-14.

11. Kiroff GK, Maddern GJ, Jamieson GG. A study of factors responsible for the efficacy of fundoplication in the treatment of gastroesophageal reflux. Aust N Z J Surg. 1984; v.54: 109-12.

12. LacyBE, WeiserK, ChertoffJ, Fass R, Pandolfino JE, RichterJE, Rothstein RI, Spangler C, Vaezi MF. The diagnosis of gastroesophageal reflux disease. Am J Med. 2010;123(7):583-92

13. Leite LP, Johnston BT, Barret J, Castell JA, Castell DO. Ineffective esophageal motility (IEM). The primary finding in patients with nonespecific esophageal motility disorder. Dig Dis Sci. 1977:42:1859-65.

14. Lemme EM, Almeida SM, Firman CM, Pantoja JP, Nascimento FA. Prolonged esophageal pH monitoring. Evaluation of 170 tests. Arq Gastroenterol. 1997;34(2):71-7.

15. Lemme EMO, Moraes-Filho JPP, Domingues G, Firman CG, Pantoja JA. Manometric findings of esophageal motor disordes in 240 Brazilian patients with non-cardic chest pain. Dis Esophag. 2000; 13: $117-21$.

16. Lord RV, DeMeester SR, Peters JH, Hagen JA, Elyssnia D, Sheth $\mathrm{CT}$, DeMeester TR. Hiatal hernia, lower esophageal sphincter incompetence, and effectiveness of Nissen fundoplication in the spectrum of gastroesophageal reflux disease. J Gastrointest Surg. 2009;13(4):602-10.

17. Mathew G, Watson DI, Myers JC, Holloway RH, Jamieson GG. Esophageal motility before and after laparoscopic Nissen fundoplication. Br J Surg. 1997; 84:1465-9.

18. Myers JC, Jamieson GG, Sullivan T, Dent J. Dysphagia and gastroesophageal junction resistance to flow following partial and total fundoplication. J Gastrointest Surg. 2012;16(3):475-85.

19. Nasi A, de Moraes-Filho JP, Cecconello I. Gastroesophageal reflux disease: an overview. Arq Gastroenterol. 2006;43(4):334-41.

20. Pessaux P, Arnaud JP, Ghavani B, Flament JB, Trebuchet G, Meyer C, Huten N, Tuech JJ, Champault and Société Française de Chirurgie Laparoscopique. Morbidity of laparoscopic fundoplication for gastroesophagfeal reflux: A retrospective study about 1470 patients. Hepatogastroenterology 2002; 49:447-450.

21. Pursnani KG, Sataloff DM, Zayas F, Castell DO. Evaluation of the anti-reflux mechanism following laparoscopic fundoplication. $\mathrm{Br} J$ Surg. 1997; 84:1157-61.

22. Richter JE, Wu WC, Johns DN, Blackwell JN, Nelson JL 3rd, Castell JA Castell DO. Esophageal manometry in 95 healthy adult volunteers. Variability of pressures with age and frequency of "abnormal" contractions. Dig Dis Sci. 1987;32(6):583-92.

23. Ruiz-Tovar J, Diez-Tabernilla M, Chames A, Morales V, MartinezMolina E. Clinical outcome at 10 years after laparoscopic versus open Nissen fundoplication. J Laparoendosc Adv Surg Tech A. 2010;20(1):21-3.

24. Slim R, Forichon J, Boulez J, Mion F. Laparoscopic fundoplication for gastroesospohageal reflux: Effects on esophageal motility. Surg Laparosc Endosc. 2000; 10: 115-19.

25. Spechler SJ, Castell DO. Classification of oesophageal motility abnormalities. Gut 2001:49:145-51.

26. Spechler SJ. Epidemiology and natural history of gastroesophageal reflux disease. Digestion 1992; 51: 240-49.

27. Wilshire $C L$, Niebisch $S$, Watson TJ, Litle VR, Peyre CG, Jones $C E$, Peters $\mathrm{JH}$. Dysphagia postfundoplication: more commonly hiatal outflow resistance than poor esophageal body motility. Surgery. 2012;152(4):584-92 